\title{
Factors in time to malaria treatment in the Brazilian Amazon: a survival analysis
}

\author{
Vinícius de Souza Maia ${ }^{\dagger}$, Bianca Cechetto Carlos $^{\dagger}$, Natália Martins Arruda, Carlos Eduardo Beluzo and \\ Luciana Correia Alves
}

\footnotetext{
${ }^{*}$ Correspondence:

viniciusmaia108@gmail.com Elza Berquó Population Studies Center, Institute of Philosophy and Human Sciences, University of Campinas, 1300 Albert Einstein Ave., Campinas/SP, BR Full list of author information is available at the end of the article tEqual contributor
}

\begin{abstract}
Background: Malaria continues to be one of the most relevant infectious diseases in Brazil and globally, with over 150.000 cases in 2019 alone. Due to high $P$. vivax prevalence and bold $P$. falciparum elimination goals, the Brazilian Malaria Elimination Program placed a high priority on timely treatment. Cases in the country are concentrated in the Legal Amazon region, with diagnosis and treatment provided for free by the government through its public health system, but many relevant questions about heterogeneity in risk and access to treatment remain.
\end{abstract}

Methods: We use data from the Malaria Epidemiological Surveillance System, maintained by the Ministry of Health, from 2007-2019 to analyze factors that affect time to treatment of malaria in three distinct periods. We use Kaplan-Meier survival functions to estimate the interval between the appearance of first symptoms and beginning of treatment for several administrative, demographic, social and health variables.

Results: Despite advances in malaria control over the last two decades, the program has not achieved its timely treatment goals in any of the periods analyzed. Malaria risk was highest among working-age adults, concentrated in a few high risk municipalities, autochthonously transmitted, in agriculture and domestic services, lower education, mid to low levels of parasitaemia, brown, indigenous and black populations and males. The main parasite is $P$. vivax and the majority of cases is still passively detected. Time-to-treatment was lower when they were detected actively, had lower levels of schooling, were not pregnant or past the 2 nd trimester, between 0 and 14 years of age, worked in agriculture, had low parasite counts, were infected with $P$. falciparum, were indigenous people and lived in high risk municipalities.

Conclusions: Differences in access to treatment were small if compared to differences in risk of acquiring malaria in the first place, but active case detection, municipal risk and race showed significant differences and potential avenues for intervention.

Keywords: Malaria epidemiology; Malaria control; Time-to-treatment

\section{Background}

Malaria continues to be one of the most relevant diseases for population health in Brazil and around the world. Globally, there were 229 million cases in 2019. In the Americas alone, there were 900 thousand cases and 552 deaths, primarily in Venezuela, Brazil and Colombia, where $86 \%$ of cases where registered [1]. In Brazil, there were 153,296 cases in 2019, with 37 deaths [2]. Despite significant strides over 
the last four decades, there are a number of challenges for malaria control and treatment, ranging from its relationship with the environment, population vulnerability, its complex epidemiology and the political and institutional arrangements necessary to implement measures against it [3].

One of the goals of the Malaria Elimination Plan in Brazil [4] is that the proportion of timely treatments should reach at least $70 \%$. The plan defines timely treatment as the one started within a given deadline from the appearance of the first symptoms. For autochtonous cases, this deadline is 48 hours, for imported cases, it is $96 \mathrm{~h}$. The importance of timely treatment is given by disease characteristics: the longer the interval between the appearance of symptoms and the beginning of treatment, the more severe the infection tends to be and the higher the risk for the disease to spread. Not only that, but severe cases can overload health services, by making treatment longer, more complex and expensive.

According to the most recent epidemiologic report [2], only 2 in 9 states in the Legal Amazon region (LA), where over 99\% of malaria cases are reported in the country, reached the $70 \%$ timely treatment goal in 2019. Considering the ecological, demographic, epidemiologic and social-political determinants of malaria [1, p. 131], it is important to identify groups under greater risk, where interventions are needed to improve timely treatment and efficient disease control in the country.

With that in mind, the objective of the current study was to measure the interval from the appearance of first symptoms to the beginning of treatment (IST - Interval Symptom-Treatment) between the years 2007 and 2019, in the LA, stratified by demographic, socioeconomic and health factors. Our hypothesis is that the malaria IST is not on the level proposed by the Malaria Control Program due to the aforementioned factors and that this analysis can help highlight effective avenues for intervention. We use data from the Malaria Epidemiological Surveillance System (SIVEP - Malaria) [5], from the Ministry of Health, as the source for the analysis.

\section{Methods}

Data was obtained from SIVEP - Malaria for the years 2007-2019. The system is a continuous administrative registry of malaria cases in the LA region, fed by compulsory report forms produced at the point of service and then gathered on a national database. Each case report is generated from results a blood test for malaria (either a thick-smear or rapid diagnostic test) and an interview with the patient, where about 40 variables are assessed. Among these, are administrative, demographic, socioeconomic, epidemiologic and health data for the service, the patient and disease.

In the survival analysis, the dependent variable was the IST measured in days between first symptoms and the beginning of treatment as registered in the case report. Since cases are registered on a date basis, we have time 0 for treatment started on the same day as first symptoms, day 1 for next day, and so on. For autochtonous cases, we censored cases after the second day (equivalent to $48 \mathrm{~h}$ ), for imported cases, after the fourth day (96h), as per the Malaria Elimination Plan's goals [2]. The results for imported cases were analyzed, but a choice was made to focus on the analysis of autochtonous cases, since they represent over $90 \%$ of the sample and since imported cases are typically within program goals. 
Results were divided in three distinct periods of recent malaria transmission in Brazil. From 2007 to 2011, there was a dramatic reduction in the total number of cases reported in the country and in the LA region, but there were still over 300 thousand cases a year on average. From 2012 to 2016, the program reached its historic minimum in 35 years, which was an inciting factor the launch of the ambitious 2016 elimination plan; we can consider this period the peak of malaria control efforts in the country. From 2017 onwards, there was a short-lived but massive increase in case reports, for which the causes and consequences for control efforts are still unclear.

Variable selection and category design was conducted as a function of their importance as risk factors for malaria, most of which was left as they are collected in case reports. The exceptions were the year of report, reduced to three periods described above, and level of schooling, reduced to four broad categories seen in table 1.

Therefore, descriptive statistics and Kaplan-Meier[6, 7] survival estimates were computed for the variables present in table 1 . The functions were evaluated using log-rank tests for statistical significance of differences in curves at the $\alpha=0.05$ level. Other than municipal risk, estimated from yearly case counts and estimated population provided by the National Institute for Geography and Statistics (IBGE), the variables presented are directly gathered in the SIVEP case report form [8].

The occupation "other" was partially created by joining the "other" category already present in the case report form with occupations that had less than $1 \%$ of total cases reported.

One of the issues with the dataset is the amount of variables with missings values, as much as $72 \%$ in some cases. For this reason, we analyze results for valid cases in each variable separately. The questionnaire has also undergone changes in the pregnancy, level of schooling and treatment administered variables in 2011, but the values of variables were harmonized between the old and new values. The treatment administered variable was not analyzed, and as such, no harmonization was needed. The level of schooling variable used to report year ranges (1-3, 4-7, etc.) which were converted to grades (1st to 4th grade elementary school, etc.), we created broad categories presented in table 1 . The pregnancy variable was changed from a binary variable to include gestational age, so it was harmonized to include "unknown gestational age" as a category for pregnant women where the information was not collected. Once variables were harmonized, the same valid case procedure was used on our univariable analyses.

Several authors have analyzed the quality and completeness of registration within SIVEP (see [9], [10] e [11]) and concluded it to be high quality and complete data on almost every variable, with a pattern of improvement over time, so that the most recent data is also the highest quality. The complete dataset for the 2007-2019 period has about 30 million observations, but we have only included positive slide tests for first time notifications. We excluded negative slide tests, because information on the patient is generally not collected then, and cure verification slides, because they represent follow up data on patients and not new infections. This process resulted in $2,745,236$ observations.

Another relevant issue is the nature of sample in question: notifications are not individuals, but instances of detected infections. This means the same individual 
may have been notified several times throughout the period, sometimes even when he should have been included as followup [12]. It also requires careful consideration of results, since it does not represent random population sampling within the LA, but a sub-population of individuals (1) tested for malaria, (2) whose tests came back positive and (3) who showed symptoms. Therefore, considering the differential risks of acquiring malaria that may exist between sub-populations, purely statistical measures of confidence that presuppose random sampling may be biased, even if they have very small p-values due to the massive sample size.

Analysis was performed using R software version 4.0.3.

\section{Results}

\section{Descriptive analysis}

Table 2 shows absolute frequencies and proportions of study variables. The variables used are the ones shown in table 1.

The decomposition in periods allows us to summarise the history of malaria control in the study period in the LA. Between 2007 and 2011, there were 1.5 million cases, an average of 300 thousand a year, although this was a period of accelerated reduction in the number of cases, most of which were concentrated in the beginning. Between 2012 and 2016, the number of cases reduced to their 35 year minimum, oscillating between 126 and 114 thousand, totalling around 700 thousand cases in 5 years. However, from 2017, the number of cases sharply increased, quickly reaching 175 thousand in 2017-18 and falling back to 142 thousand in 2019, with around 500 thousand cases in just three years.

The majority of notifications are in the adult population (15-64 years old), in high risk municipalities, authoctnously transmitted, in agriculture and domestic services, lower education, mid to low levels of parasitaemia, brown, indigenous and black people, $P$. vivax, males and passive case detection. This pattern has remained relatively stable during the three periods, but there were some relevant changes. The proportion of older individuals has been steadily increasing, the proportion of agricultural workers fell sharply, but recovered in the last period, gold panning and mining has also seen a decrease in the last period and there was a large increase in uncategorized "Other" activities. The level of schooling pattern has been shifting towards higher levels of education in a significant way and the racial composition has become much more heavily skewed towards native indigenous populations, whose proportions are now 5 times that of the first period and finally, the main parasite species has become even more overwhelmingly $P$. vivax.

\section{Kaplan-Meier}

With respect to survival analysis, some aspects of this data differ from standard followup studies, which usually have longer and more heterogeneous follow-up times. This usually results in very distinctive survival trajectories for relevant factors. In this analysis, the records have very homogeneous times, since censoring happens very quickly (day 2) and differences between groups tend to be relatively small (a few percentage points), therefore, graphical representations did not help readers visually distinguish between groups very well, even with a log transformation, reason why we decided for a table presentation of results. We also chose to use the event 
function, rather than the survival function, since it more readily represented the desired outcome of early and opportune treatment and higher proportions represent better results.

Table 3 shows Kaplan-Meier estimates for opportune treatment proportions and respective p-values for log-ranks tests for the LA region in all three periods of analysis.

When analyzing overall cases, even excluding imported cases ${ }^{[1]}$, only $63 \%$ of notifications had adequate IST in the first and second periods, and this percentage fell to $61 \%$ in the final period.

Patients were more likely to have lower ISTs if they were detected actively, had lower levels of schooling, were not pregnant or were past the 2nd trimester of pregnancy, were between 0 and 14 years of age, worked in agriculture, had low parasite counts, were infected with $P$. falciparum, were native indigenous and lived in high risk municipalities. There was little difference between male and female patients.

Over time, the trends remained relatively stable, with a general trend for lower ISTs in the period 2012-2016 and an increase in ISTs in the 2017-2019 period. The exceptions were race, which showed an increased IST for native populations in the second period and a decrease for whites, parasite count, whose IST for high parasite counts has decreased in both periods, pregnancy status, which decreased ISTs for pregnant women after the first period, and schooling, where higher levels of education have worsening ISTs in the third period.

The parasite count variable seems to show signs of time-dependency ${ }^{[2]}$, since there is an increase in IST concurrently with an increased parasite count for all categories except the highest.

\section{Discussion}

This analysis has a similar goal to the work of Lima and Duarte [13], however, using a different methodology, updating results for a more recent time frame and introducing distinct periods of malaria incidence and control in the country. We have also chosen to deal with the spatial component distinctly: while the authors of that study used Federative Units (or States), we chose to group municipalities by risk, since the disease is much more spatially concentrated now than in the last few decades $[5,14]$. About the study results, they found that incidence was highest among children and young adults ( $\mathrm{i} 30$ yo.), males, black people, who resided in the state of Amazonas. In their analysis of IST, children up to 14 yo. showed the best results, but sex and year of treatment showed no significant differences. They did not analyze other variables. In their multivariate logistical model, children and young people up to 29 yo., indigenous people, Acre, Rondônia or Roraima state residents and people treated in the year 2013 had higher odds of being treated in a timely manner. These results are quite consistent with the ones presented here, despite the distinct methodologies.

[1] Imported cases had higher median time to treatment, but higher proportions of timely treatments since their deadline for timely treatment was longer - 96 hours or 4 days.

${ }^{[2]}$ In survival analysis, it is said of variables whose effect on the outcome isn't stable over the period, but changes in some way throughout it. 
The drop in number of cases in the 2007-2019 period was associated to the effectiveness of the program and changes in occupations and economic activities in the region $[3,15]$. This very same trend which culminated in the historic low incidences registered in 2016 led to what some experts termed "complacency" towards the goal of malaria elimination [16], which could have been a contributing factor to the nearly $50 \%$ increase the next year. Another possibility is that environmental factors such as extreme drought brought on by El Niño in the 2014-2016 period may have temporarily contributed to a decrease in incidence and the sudden increase observed in 2017 represented a "return to normal" in a way, as well as a shift in focus towards the then emergent dengue, Zika and Chikungunya epidemics [17, 18].

Our hypothesis was that population characteristics would weigh on the IST, and that was corroborated by our results, even though not all variables selected showed significant differences. Variables for gender, pregnancy status, schooling and occupation showed smaller differences, while variables for case detection, age, race and municipal risk showed significant differences between categories. Results have also shown that the overall IST has stayed below program goals (at around 62\% throughout the period) and has actually worsened in the most recent period.

In more practical terms, the results of this study reinforce the relevance of timely treatment towards lowering infection severity and disease spread, as well as provide evidence that active detection can actually lower IST significantly, considering that time for actively detected cases was much shorter than for passive ones. Patients with shorter ISTs also showed lower parasite counts (3). Consequently, it is possible that an increase in the proportion of actively detected cases leads to an even greater reduction of ISTs and lower parasite counts.

The LA region concentrates over $99 \%$ of malaria cases, but these cases are not uniformly distributed. Between 30 and 40 municipalities concentrate about $80 \%$ of annual cases and results show that municipalities where malaria is most prevalent have lower ISTs than lower risk settings (3), similar to what was shown by others $[2,19]$. Malaria concentration in a few municipalities shows an advanced stages in disease control and elimination in the country, but there is much to be done yet. Although this concentration shows that control measures so far have been effective and most municipalities in the region have practically no local transmission, high ecological receptivity and vector availability represent high risk for reintroduction and outbreaks [20].

Considering that autochtonous cases represent the majority of cases in the region $(89 \%)$ at the municipal level, this study chose to analyze this form of transmission primarily. However, we highlight the importance of case importation for two reasons: (1) case importation can be very significant locally, such as the case of cross-border malaria and a few high-risk municipalities [21, 22] where population mobility is a key driver of malaria transmission, (2) reintroduction is a very real possibility given the high ecological receptivity for vectors of disease. An example of this was observed in 2017 when a few municipalities registered massive outbreaks [16] in areas where risk had already diminished considerably.

Moving on to more specific results, we chose to split age groups according to malaria infection risk. Up until 15 years of age, it is expected for individuals to be subject to peridomestic risk and responsibility for healthcare provision lies on 
their parents or caretakers. From 15 to 64 years, risks tend to be more related to occupation and work related activities. After 65 , peridomestic risks compound with the general health frailty of an older population.

According to [23], the main victims of malaria worldwide are african children. In the LA case, the level of malaria mortality is quite low. In 2019, for example, there were 26 deaths in 157 thousand notified cases [5]. The distribution of these deaths can be seen in [24] and we highlight that for most states, these deaths occur in adult or senior populations, rather than in children.

Our results show that about $60 \%$ of cases are concentrated in the 15 to 64 yo. population and to a lesser extent (35\%), on the 0 to 14 yos (2). In our analysis of IST (3), the 0 to 14 yo. population has a shorter IST and it is closest to program goals, while the over 15 population has much longer ISTs. According to estimates presented by [25], malaria mortality levels for the Amazon region as a whole are less than 0.1 deaths per 1000 population, however, the proportion of these deaths is highest on $70+$ yos., which could be related to the higher ISTs. At the same time, the population levels for 0 to 14 yo. are the same as the general mean level, which could be related to the lower ISTs. It is important to keep in mind that we're discussing very low levels of mortality in the Amazon region if compared to other regions of the world where $P$. falciparum prevalence is much higher than $P$. vivax.

Differences between men and women shown in case counts and proportions (2) did not carry over to the IST analysis (3). We believe these results to mean that differences are related to infection risk rather than treatment access, considering males tend to have higher participation in jobs that increase their exposure such as gold mining, agriculture, forestry, where over $80 \%$ of malaria cases affect males.

This is also observed with the cases of pregnant women. Despite their low proportion (about $5 \%$ of total cases), this is a population with additional risks related to maternal and child health, with restrictions on available treatment regimens [3]. Our analysis (3) has shown that differences in IST between pregnant and non-pregnant women have diminished over the years.

Because of the small sample of pregnant women, there is a lot of overlap between confidence intervals for different categories, even though the log-rank tests showed significant differences. In the case of gender and pregnancy status, we believe the observed differences were not practically significant even if they were statistically so.

Socioeconomic disparities related to malaria risk were analyzed by several authors $[26,27]$, so any variables available in the dataset pertaining to these characteristics of patients were included for analysis.

The first one is the occupation of patients. Historically in LA, mining, gold panning and forestry were high-exposure occupations [28, 29] due to their environmental impact, poor living conditions, remoteness and low access to health services. It is also important to highlight the relationship between malaria and gold mining/panning as a major source of disease in the areas where it is done, because the nature of the activity itself favors contact with and proliferation of mosquitoes [30-32].

Recently, a few authors focused on the importance of mobility for malaria transmission [17, 22], which includes mobile occupations. Individuals who declared their 
occupations to be travel-related had the lowest proportions of IST $(55 \%)^{[3]}$, which provides evidence that these high risk individuals can stay infected and transmissible for longer periods, a particularly risky proposition considering they may carry disease between places.

The most relevant occupations numerically were agriculture and domestic service. Agriculture alone was responsible for one quarter of all cases registered (2), even though their IST was above average (3). The second largest category was domestic service, with $11 \%$ of all cases. This group, in theory, should be less vulnerable to outdoor mosquito bites. The IST for domestic service occupations worsened somewhat during the period, going from 61 to $57 \%$, which may have been a factor on the uptick in malaria cases in 2017-2019. Together these two categories represent over a third of all cases, and as such, carry a significant weight to the achievement of the program goal of $70 \%$ of cases treated within $48 \mathrm{~h}$ of showing symptoms.

The combination of inadequate living conditions, low access to health services and low treatment compliance are oft-related characteristics of populations with low levels of schooling. What our results have shown, however, is that while these populations are high risk for infection (2), they actually have much better ISTs than higher education strata (3). This results seems to suggest that malaria incidence on low schooling populations is more related to infection exposure than to any differentials in access to treatment.

Another schooling related issue was a simultaneous increase the proportion of higher levels of schooling in total cases over the periods (2) and higher ISTs for this population (3). At least in relation to case counts, we believe this may be partly explained by increases in the overall level of schooling of the region population, however, this does not explain why this population has longer time to treatment. Further research on this is needed.

On the race variable, most cases affect brown and indigenous populations, which is concerning because these are historically marginalized groups not only in healthrelated issues. This is true even considering the proportion of these groups in total population. According to the 2010 Demographic Census [33], the brown population is $65 \%$ of the LA population, but they account for $73 \%$ of cases, the indigenous population is only $2 \%$ of LA total, but accounts for $15 \%$ of malaria cases. By contrast, $25 \%$ of LA is white, but only $6.4 \%$ of malaria cases (2). This variable contains a large amount of missing values, but they belong to the 2007-2013 period before the variable was introduced.

There is a lot of overlap between these high risk populations and low levels of schooling, which in terms of IST means that their results are superior, since they mostly seek treatment in the public network, where health professionals are better trained to identify and treat malaria [13,34]. However, the brown population IST has worsened in recent years (from 63 to $58 \%$ in 2017-2019) which may have been a contributing factor to the rebound in cases. Another concerning issue is that the black population, although a minority in proportion of total cases (4.5, down to $3 \%$ in the last period) has had a major increase in IST (60 to $53 \%$ of timely treatments). This trend of worsening treatment times does not bode well for the ambitious goals of $P$. falciparum elimination.

\footnotetext{
${ }^{[3]}$ Results not shown
} 
An optimistic interpretation of these results is that control strategies have reduced malaria transmission in areas where the health system is more firmly established, but recent trends in economic activity and migration have pushed populations into new areas where health infrastructure is insufficient or nonexistent, therefore worsening ISTs, but current research seems to point in the direction of a shift in priorities from malaria to other diseases (zika, dengue, chikungunya) and poorly understood local and long-distance transmission networks that contribute to high malaria prevalence in some areas $[3,17,22]$ as the main drivers of this worsening performance.

After a period of accelerated reduction of malaria falciparum cases in the 2000s $[3,35], P$. vivax became the dominant species, totaling $90 \%$ of cases in the most recent period (2), a result of $P$. falciparum elimination efforts and available of new and effective treatments. Since $P$. falciparum is responsible for the more severe and deadly forms of malaria, its elimination became a priority for the program from 2003. Vivax malaria, on the other hand, presents a series of challenges to its elimination, such as longer treatment courses, submicroscopic infections, resistance to current treatments, asymptomatic infections, and others $[3,12,36]$, all of which pose major obstacles to elimination.

Despite current progress on P. falciparum reduction, there were still 37.319 cases in the last period (2), a number that should not be taken lightly, given concerns of artemisinin-resistant strains [3] and ecological receptivity of the region [17] to species reintroduction in currently low-risk settings in the region. There were no major differences between ISTs for both Plasmodium spp., but infections with $P$. falciparum gametocytes had significantly longer ISTs, which makes sense, given that delayed treatments allow the parasite to complete more reproduction cycles.

When it comes to parasite count ${ }^{[4]}$, most infections were in the low end of the spectrum (2), about $40 \%$ had less than 300 parasites $/ \mathrm{mm}^{3}$ of blood, and $60 \%$ had less than 500 parasites $/ \mathrm{mm}^{3}$ of blood. The analysis of IST showed evidence of timedependence, considering that the best IST values were detected for lower parasite densities, meaning that faster treatments prevent parasites from continuing to multiply, similar to what was observed for P. falciparum gametocytes. Although this relationship was not observed for the slides detected with four crosses, the percentage of patients who presented this parasitemia did not exceed $0.1 \%$ of the cases. Despite the relationship between parasite count and severe malaria has many particularities, higher parasitaemia have more chance to promote more severe infections [37].

The relation between IST and type of detection (active or passive) showed that active anticipates the beginning of treatment demonstrating an important difference in the proportion of treated opportunely when compared with passive detection. Active detection has steadily approached $70 \%$ of cases treated in the first $48 \mathrm{~h}$ while passive detection cases had much lower proportions of timely treatment, with only $61 \%$ in the first period, falling to $58 \%$ in the last.

According to [18], a malaria notification should start a process of investigation and control at the probable location of infection, with deployment of tests on all individuals near the area. A lot of progress has been made in this direction, with

${ }^{[4]}$ There were no major differences between parasite counts for $P$. vivax and P. falciparum 
over $60 \%$ of slides now being related to active detection efforts [36]. The relatively low proportion of active slides in our sample is related to our case selection strategy, which uses only positive slide tests.

A note about statistically significant results: due to the large sample size, nearly every statistical test that can be performed, even with stratified samples resulted in p-values $<0.001$. This does not mean that we can consider these differences significant. To cite an example, gender differences in IST were only a percentage point, which we do not believe provide evidence that there is a significant difference in treatment times for men and women. We agree with [38], which concludes that statistically significant results need to be supplemented by clinically significant ones in order to support interventions, since large databases tend to produce robust confidence measures regardless.

The dataset itself also merits a few remarks: it provides continuous data since 2003 (although we have used the data since 2007 here), with daily resolution and large sample sizes in varying geographical levels. With a few tweaks, it could be leveraged to provide longitudinal data on malaria infections, allowing for studies on treatment effectiveness and recurrences (such as the one conducted by [12]). It does however, suffer from a few issues. Variables such as occupation have high proportions of "other" declared, which compromises analysis. It is possible that a more complete database of occupations could provide insights into changes in economic activity and malaria risk. Age reporting could stand to improve, since nearly $12 \%$ of notifications in 2019 still have no date-of-birth, but only simple declared age. There is also a small proportion of incorrect date reports in several variables, which could be easily improved. A more complicated and major change would be to collect data on negative slides, since it is currently not possible to calculate measures related to population characteristics considering we only have data on positive tests. Perhaps a sampling method could be used to collect data on some negative slides as a control, since negative slides account for over $90 \%$ of all samples.

\section{Limitations}

As with many observational studies, the authors of this paper do not have control over study design, quality of data reporting and possible confounding variables. Moreover, SIVEP is an administrative record of the Ministry of Health and not a result of a scientific data collection effort. These limitations are offset by two factors: the quality of registry data has been verified by other researchers $[9,10]$ and this is the best available population level data about malaria in LA.

We would also highlight two other issues: the first is that the main outcome of interest in studies of treatments is not available to us, which would be whether or not treatment was effective for patients. This has two main reasons: one is that data is not available for patients whose notifications came back negative, and the other is that there is no unique patient identifier; this leads to the second problem: notifications may be related to repeat or recurrent infections. We have attempted to circumvent this problem somewhat by eliminating cure verification slides, but some repeat infections and recurrences may be registered as new cases [12]. Both of these problems might be easily circumvented by making unique anonymous patient 
ID available. There is already a study [12] using linked SIVEP data, but data allowing patient identification is not usually made available to researchers for privacy considerations. As a result, we are restricted to an analysis of time to beginning of treatment. Further studies using linked SIVEP data on treatment efficacy would be welcome, as well as studies that explore time-to-treatment with other methodologies, such as statistical or machine learning models.

\section{Conclusions}

In summary, the results show that early diagnostic and treatment can have a significant impact on disease transmission, since it can reduce exposure times for infected patients to anopheles vectors. In this context, strategies that reduce this window, such as active detection, tend to become increasingly relevant as overall levels of incidence fall, since vector control strategies have limited effectiveness in the LA ecosystem.

When considering sociodemographic determinants, the results highlight that differences are mostly related to infection exposure rather than access to treatment. When ISTs were analyzed, variables such as gender and pregnancy status showed insignificant differences, while schooling, race and occupation had larger effects, but not in the expected direction. Socially disadvantaged populations actually had lower ISTs, which means they received their treatments more quickly than privileged groups. Their disadvantage seems much more related to their risk of acquiring malaria in the first place, through precarious living conditions or occupational exposure, for example. In fact, if we compare the 2012-2016 lowest transmission period with the most recent one, the differences in IST between levels of schooling increased, which suggests an increase in heterogeneity of malaria transmission contexts even as overall levels of transmission decrease [14].

With that in mind, the most relevant indicators were case detection and municipal risk. These have shown the largest differences between groups, as well as reflect variables were intervention may be significant through surveillance and control measures. When considering health variables, this paper corroborates prior findings that early treatment is effective in reducing disease spread.

In conclusion, there are significant differences among populations groups in the LA region both in terms of malaria infection risk and treatment times, and there is room for data oriented effective interventions. We hope this article contributes to an understanding of malaria as a population health issue, that affects large contingents of people in a social, economic and infrastructural context that defines malaria control in Brazil.

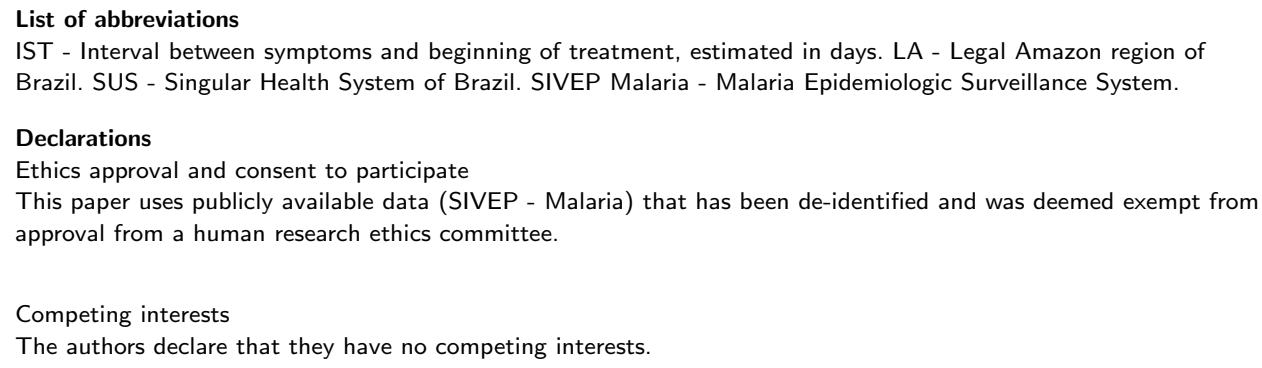


Author's contributions

VSM conceived the study, conducted data analyses and drafted the original manuscript. BCC performed major revision and data interpretation. NMA performed data quality assessment and cleaning. All authors curated the data, interpreted results, revised the manuscript and agree with the submitted version.

Funding

This work was supported by the Bill and Melinda Gates Foundation and National Council for Scientific and Technological Development (CNPq - Conselho Nacional de Desenvolvimento Científico e Tecnológico) (443048/2019-3).

Consent for publication

Not applicable.

Availability of data and materials

Data used in this study is not publicly available but can be obtained through a Lei de Acesso a Informação (Access to Information Law) request to the Ministry of Health.

Author details

All authors are affiliated to Elza Berquó Population Studies Center, Institute of Philosophy and Human Sciences, University of Campinas, Campinas/SP, Brazil.

\section{References}

1. World Health Organization. World Health Organization, editor. World malaria report 2020. World Health Organization; 2020. Available from: https://www.who.int/publications/i/item/9789240015791.

2. Secretaria de Vigilância em Saúde. Ministério da Saúde, editor. Boletim Epidemiológico. Ministério da Saúde; 2020. Available from: https://www.gov.br/saude/pt-br/media/pdf/2020/dezembro/03/boletim_ especial_malaria_1dez20_final.pdf.

3. Ferreira MU, Castro MC. Challenges for malaria elimination in Brazil. Malaria Journal. 2016 May;15(1).

4. Ministério da Saúde. Ministério da Saúde, editor. Plano de Eliminação da Malária no Brasil. Ministério da Saúde; 2016.

5. Ministério da Saúde. Secretaria de Vigilãncia em Saúde, editor. SIVEP - Malária. Ministério da Saúde; 2020. Available from: http://portalweb04.saude.gov.br/sivep_malaria/.

6. Kaplan EL, Meier P. Nonparametric Estimation from Incomplete Observations. Journal of the American Statistical Association. 1958;53(282):457-481. Available from: https://www. tandfonline.com/doi/abs/10.1080/01621459.1958.10501452.

7. Carvalho MS, Andreozzi VL, Codeço CT, Campos DP, Barbosa MTS, Shimakura SE. Análise de sobrevivência: teoria e aplicações em saúde. Rio de Janeiro: SciELO - Editora FIOCRUZ; 2011.

8. Ministério da Saúde. Ministério da Saúde, editor. Ficha de Notificação de caso de Malária - SIVEP. Ministério da Saúde; 2020.

9. Wiefels A, Wolfarth-Couto B, Filizola N, Durieux L, Mangeas M. Accuracy of the malaria epidemiological surveillance system data in the state of Amazonas [Exatidão dos dados do sistema de vigilância epidemiológica da malária no estado do Amazonas]. Acta Amazonica. 2016;46(4):383-390. Cited By 8. Available from: https: //www . scopus. com/inward/record.uri?eid=2-s2.0-84981710117\&doi=10.1590/ 1809-4392201600285\&partner ID $=40 \& \mathrm{md5}=\mathrm{f} 6 \mathrm{~b} 3176 \mathrm{e} 4516 \mathrm{e} 3354 \mathrm{e} 65 \mathrm{f}$ adc $13 \mathrm{e} 05398$.

10. Braz RM, Tauil PL, e Silva Santelli ACF, Fontes CJF. Avaliação da completude e da oportunidade das notificações de malária na Amazônia Brasileira, 2003-2012. Epidemiologia e Serviços de Saúde. 2016 Jan;25(1):10-1. Cited By 9. Available from:

https : //www . scopus . com/inward/record . uri?eid=2-s2 . 0-85021650553\&doi=10.5123/ S1679-49742016000100003\&partnerID=40\&md5=14bbb4bff $7 \mathrm{f} 6 \mathrm{a} 4 \mathrm{aa} 0 \mathrm{f} 92 \mathrm{ca} 1 \mathrm{cc} 2 \mathrm{f} 23392$.

11. Braz RM, Oliveira PdTRd, dos Reis AT, da Silva Machado NM. Avaliação da completude da variável raça/cor nos sistemas nacionais de informação em saúde para aferição da equidade étnico-racial em indicadores usados pelo Índice de Desempenho do Sistema Único de Saúde. Saúde em Debate. 2013 Dec;37(99):554-562.

12. Daher A, Silva JCAL, Stevens A, Marchesini P, Fontes CJ, Kuile FOT, et al. Evaluation of Plasmodium vivax malaria recurrence in Brazil. Malaria Journal. 2019 Jan;18(1). Cited By 7.

13. Lima IdSF, Duarte EC. Factors associated with timely treatment of malaria in the Brazilian Amazon: a 10-year population-based study. Revista panamericana de salud publica. 2017 Aug;41. Available from: https://www.ncbi.nlm.nih.gov/pmc/articles/PMC6660879/\#B24.

14. Lana R, Nekkab N, Siqueira AM, Peterka C, Marchesini P, Lacerda M, et al. The top $1 \%$ : quantifying the unequal distribution of malaria in Brazil. Malaria Journal. 2021 Feb;20(1).

15. Lapouble OMM, Santelli ACFeS, Muniz-Junqueira MI. Situação epidemiológica da malária na região amazônica brasileira, 2003 a 2012. Pan American journal of public health. 2015 Oct;38(4):300-306. Cited By 14. Available from: https://www. scopus . com/inward/record. uri?eid=2-s2.0-85014388547\&partner ID=40\& md5 $=8 \mathrm{c} 1 \mathrm{a} 8 \mathrm{eb} 141 \mathrm{e} 7048923544 \mathrm{f} 725 \mathrm{f} 9863 \mathrm{~d} 1$.

16. Rossi A. Por que os casos de malária cresceram 50\% no Brasil após 6 anos de queda. BBC News Brasil. 2018 May;Available from: https://www.bbc.com/portuguese/brasil-43998843.

17. Carlos BC, Rona LDP, Christophides GK, Souza-Neto JA. A comprehensive analysis of malaria transmission in Brazil. Pathogens and global health. 2019 Feb;113:1-13.

18. Secretaria de Vigilância em Saúde. Ministério da Saúde, editor. Guia de Vigilância em Saúde. Ministério da Saúde; 2017. 
19. Braz RM, Barcellos C. Análise do processo de eliminação da transmissão da malária na Amazônia brasileira com abordagem espacial da variação da incidência da doença em 2016. Epidemiologia e Serviços de Saúde. 2018 Nov;27(3). Cited By 2.

20. Cohen JM, Moonen B, Snow RW, Smith DL. How absolute is zero? An evaluation of historical and current definitions of malaria elimination. Malaria Journal. 2010;9(1):213. Available from: https://doi.org/10.1186/1475-2875-9-213.

21. Arisco NJ, Peterka C, Castro MC. Cross-border malaria in Northern Brazil. Malaria Journal. 2021;20(1).

22. Johansen IC, Rodrigues PT, Ferreira MU. Human mobility and urban malaria risk in the main transmission hotspot of Amazonian Brazil. PLOS ONE. 2020 Nov;15(11):e0242357.

23. White NJ, Pukrittayakamee S, Hien TT, Faiz MA, Mokuolu OA, Dondorp AM. Malaria. The Lancet. 2014;383(9918):723-735. Available from:

http://www.sciencedirect.com/science/article/pii/S0140673613600240.

24. Arruda NM. Visualização interativa taxasMalaria [website]; 2020. Available from: https://arrudanat. shinyapps.io/taxasMalaria/.

25. Roser M, Ritchie H. Malaria. Our World in Data. 2013;Https://ourworldindata.org/malaria.

26. Lana RM, Riback TIS, Lima TFM, da Silva-Nunes M, Cruz OG, Oliveira FGS, et al. Socioeconomic and demographic characterization of an endemic malaria region in Brazil by multiple correspondence analysis. Malaria Journal. 2017 Oct;16(1).

27. Canelas T, Castillo-Salgado C, Baquero OS, Ribeiro H. Environmental and socioeconomic analysis of malaria transmission in the Brazilian Amazon, 2010-2015. Revista de Saúde Pública. 2019 May:53:49.

28. Monteiro THA, do Socorro Souza Chaves T, de Matos HJ, de Lisboa Sofffiatti NF, de Paula Souza e Guimarães RJ, Guimarães LHR, et al. Basic sanitation, socioeconomic conditions, and degree of risk for the presence and maintenance of malaria in a low-transmission area in the Brazilian Amazon. Revista da Sociedade Brasileira de Medicina Tropical. 2015 Oct;48(5):573-579. Cited By 4. Available from: https://www.scopus. com/inward/record.uri?eid=2-s2.0-84947417391\&doi=10.1590/ 0037-8682-0118-2015\&partnerID=40\&md5=f $327 \mathrm{f} 18 \mathrm{f} 9 \mathrm{dea} 5 \mathrm{f} 08 \mathrm{~b} 7 \mathrm{dcb} 78 \mathrm{c} 0 \mathrm{~b} 880 \mathrm{~d} 95$.

29. Duarte EC, Ramalho WM, Tauil PL, Fontes CJF, Pang L. The changing distribution of malaria in the Brazilian Amazon, 2003-2004 and 2008-2009. Revista da Sociedade Brasileira de Medicina Tropical. 2014 Dec;47(6):763-769.

30. Castellanos A, Chaparro-Narváez P, Morales-Plaza CD, Alzate A, Padilla J, Arévalo M, et al. Malaria in gold-mining areas in Colombia. Memórias do Instituto Oswaldo Cruz. 2016 Jan;111(1):59-66.

31. Braz RM, Duarte EC, Tauil PL. Caracterização das epidemias de malária nos municípios da Amazônia Brasileira em 2010. Cadernos de Saúde Pública. 2013 May;29(5):935-944.

32. Terças-Trettel ACP, Melo AVGd, Bonilha SMF, Moraes JMd, Oliveira RCd, Guterres A, et al. Hantavirus pulmonary syndrome in children: case report and case series from an endemic area of Brazil. Revista do Instituto de Medicina Tropical de Sao Paulo. 2019;61:e65.

33. Instituto Brasileiro de Geografia e Estatística. Instituto Brasileiro de Geografia e Estatística, editor. Censo Demográfico 2010. Instituto Brasileiro de Geografia e Estatística; 2010. Available from: https://censo2010.ibge.gov.br/.

34. World Health Organization. World malaria report 2014; 2014.

35. de Pina-Costa A, Brasil P, Di Santi SM, de Araujo MP, Suárez-Mutis MC, Santelli ACFeS, et al. Malaria in Brazil: what happens outside the Amazonian endemic region. Memorias do Instituto Oswaldo Cruz. 2014 Aug;109:618-633.

36. Siqueira AM, Mesones-Lapouble O, Marchesini P, de Souza Sampaio V, Brasil P, Tauil PL, et al. Plasmodium vivax Landscape in Brazil: Scenario and Challenges. The American Journal of Tropical Medicine and Hygiene. 2016 Oct;95(6 Suppl):87-96.

37. Tangpukdee N, Krudsood S, Kano S, Wilairatana P. Falciparum malaria parasitemia index for predicting severe malaria. International journal of laboratory hematology. 2012 Jun;34:320-327.

38. Simões LR, Jr ERA, Ribatski-Silva D, Gomes LT, Nery AF, Fontes CJF. Factors associated with recurrent Plasmodium vivax malaria in Porto Velho, Rondônia State, Brazil, 2009. Cadernos de Saúde Pública. 2014 Jul;30(7):1403-1417.

Tables

Table 1: Variables analyzed

\begin{tabular}{|c|c|c|}
\hline Name & Description & Category \\
\hline Age groups & $\begin{array}{l}\text { Age of patient in years, by } \\
\text { group }\end{array}$ & $\begin{array}{l}0 \text { to } 14 \\
15 \text { to } 64 \\
65 \text { or more }\end{array}$ \\
\hline Year & Year of case report & $2007-2019$ \\
\hline Parasite count (crosses) & $\begin{array}{l}\text { Amount of parasites by } \\
\mathrm{mm}^{3} \text { of blood }\end{array}$ & $\begin{array}{l}<1 / 2=<300 \\
1=301-500 \\
2=501-10.000 \\
3=10.000-100.000 \\
4=>100.000\end{array}$ \\
\hline
\end{tabular}


Table 1: Variables analyzed (continued)

\begin{tabular}{|c|c|c|}
\hline Name & Description & Category \\
\hline Detection & Form of case detection & $\begin{array}{l}\text { Active } \\
\text { Passive }\end{array}$ \\
\hline Level of schooling & $\begin{array}{l}\text { Highest educational } \\
\text { attainment }\end{array}$ & $\begin{array}{l}\text { Elementary - Incomplete } \\
\text { High school - Incomplete } \\
\text { College - Incomplete } \\
\text { College - Complete }\end{array}$ \\
\hline Pregnancy status & Status and gestational age & $\begin{array}{l}\text { Non-pregnant } \\
\text { 1st trimester } \\
\text { 2nd trimester } \\
\text { 3rd trimester } \\
\text { Pregnant, age ignored }\end{array}$ \\
\hline Municipal risk & $\begin{array}{l}\text { Level of risk assessed by the } \\
\text { Annual Parasite Index }\end{array}$ & $\begin{array}{l}\text { Low }=<10 \text { cases per } 1000 \text { population } \\
\text { Medium }=10-50 \text { cases per } 1000 \text { population } \\
\text { High }=>50 \text { cases per } 1000 \text { population }\end{array}$ \\
\hline Occupation & $\begin{array}{l}\text { Economic activity of the } \\
\text { patient in the two weeks } \\
\text { prior to infection }\end{array}$ & $\begin{array}{l}\text { Agriculture } \\
\text { Domestic service } \\
\text { Gold panning/mining } \\
\text { Other }\end{array}$ \\
\hline Parasite species & $\begin{array}{l}\text { Parasite species detected in } \\
\text { microscopy }\end{array}$ & $\begin{array}{l}\text { P. falciparum } \\
P . \text { vivax } \\
P . f . \text { gametocytes }(g P f) \\
\text { Mixed } \\
\text { Other }\end{array}$ \\
\hline Race & Race of the patient & $\begin{array}{l}\text { White } \\
\text { Black } \\
\text { Yellow } \\
\text { Brown } \\
\text { Indigenous }\end{array}$ \\
\hline Sex & Patient sex & $\begin{array}{l}\text { Male } \\
\text { Female }\end{array}$ \\
\hline
\end{tabular}

Source: SIVEP Malária, Ministry of Health, 2007-2019

Table 2: Malaria Notifications, Legal Amazon, 2007-2019

\begin{tabular}{llll}
\hline Characteristic & $2007-2011, \mathrm{~N}=1,512,891$ & $2012-2016, \mathrm{~N}=737,775$ & $2017-2019 . \mathrm{N}=494,570$ \\
\hline Age group & & & $164,931(0.33)$ \\
$\quad$ to 14 & $551,939(0.36)$ & $258,068(0.35)$ & $315,771(0.64)$ \\
15 to 64 & $931,702(0.62)$ & $462,507(0.63)$ & $13,868(0.03)$ \\
$\quad 65+$ & $29,250(0.02)$ & $17,200(0.02)$ & $366,133(0.74)$ \\
Municipal risk & & & $93,109(0.19)$ \\
$\quad$ High & $1,140,362(0.75)$ & $542,178(0.73)$ & $35,328(0.07)$ \\
Medium & $306,208(0.20)$ & $145,680(0.20)$ & $444,578(0.90)$ \\
Low & $66,321(0.04)$ & $49,917(0.07)$ & $49,992(0.1)$ \\
Imported status & & & $114,756(0.23)$ \\
$\quad$ Autochtonous & $1,333,877(0.88)$ & $665,546(0.90)$ & $49,543(0.10)$ \\
Imported & $179,014(0.12)$ & $72,229(0.1)$ & $17,154(0.03)$ \\
Ocupation & & & $313,117(0.63)$ \\
$\quad$ Agriculture & $368,982(0.29)$ & $141,447(0.19)$ & 0
\end{tabular}




\begin{tabular}{|c|c|c|c|}
\hline \multicolumn{4}{|l|}{ Pregnancy status } \\
\hline 1st trimester & $478(0.01)$ & $3,034(0.02)$ & $1,931(0.01)$ \\
\hline 2nd trimester & $811(0.02)$ & $3,734(0.02)$ & $2,433(0.02)$ \\
\hline 3rd trimester & $544(0.01)$ & $3,630(0.02)$ & $2,291(0.02)$ \\
\hline Pregnant, age ignored & $19,607(0.04)$ & $973(0.01)$ & $383(0.01)$ \\
\hline Non-pregnant & $422,436(0.95)$ & $179,600(0.94)$ & $121,083(0.95)$ \\
\hline - & $1,069,015$ & 546,804 & 366,449 \\
\hline \multicolumn{4}{|l|}{ Level of schooling } \\
\hline Elementary - incomplete & $1,137,671(0.85)$ & $485,329(0.74)$ & $302,634(0.70)$ \\
\hline High school - Incomplete & $149,845(0.11)$ & $102,319(0.16)$ & $72,091(0.17)$ \\
\hline College - Incomplete & $45,982(0.03)$ & $59,591(0.09)$ & $54,293(0.12)$ \\
\hline College - Complete & $560(0.01)$ & $5,764(0.01)$ & $5,817(0.01)$ \\
\hline- & 178,833 & 84,772 & 59,735 \\
\hline \multicolumn{4}{|l|}{ Parasite count (crosses) } \\
\hline i $1 / 2$ & $577,457(0.38)$ & $311,015(0.42)$ & $201,920(0.41)$ \\
\hline 1 & $323,428(0.21)$ & $142,453(0.19)$ & $93,998(0.19)$ \\
\hline 2 & $568,650(0.38)$ & $265,989(0.36)$ & $187,226(0.38)$ \\
\hline 3 & $41,569(0.03)$ & $17,622(0.02)$ & $11,078(0.02)$ \\
\hline 4 & $1,787(0.01)$ & $696(0.01)$ & $348(0.01)$ \\
\hline \multicolumn{4}{|l|}{ Race } \\
\hline White & $13,724(0.06)$ & $53,107(0.07)$ & $27,922(0.06)$ \\
\hline Black & $10,087(0.04)$ & $33,564(0.04)$ & $14,846(0.03)$ \\
\hline Yellow & $2,380(0.01)$ & $7,671(0.01)$ & $3,048(0.01)$ \\
\hline Brown & $206,491(0.85)$ & $526,681(0.71)$ & $342,391(0.69)$ \\
\hline Indigenous & $9,405(0.04)$ & $116,752(0.16)$ & $106,363(0.22)$ \\
\hline- & $1,270,804$ & 0 & 0 \\
\hline \multicolumn{4}{|l|}{ Parasite species } \\
\hline P. falciparum & $195,805(0.13)$ & $77,430(0.10)$ & $37,319(0.07)$ \\
\hline$g P f^{3}$ & $35,038(0.02)$ & $17,183(0.02)$ & $10,623(0.02)$ \\
\hline P. vivax & $1,271,167(0.84)$ & $637,629(0.86)$ & $444,516(0.90)$ \\
\hline Mixed & $10,341(0.01)$ & $5,366(0.01)$ & $2,069(0.01)$ \\
\hline Other & $540(0.01)$ & $167(0.01)$ & $43(0.01)$ \\
\hline \multicolumn{4}{|l|}{ Gender } \\
\hline Male & $933,111(0.62)$ & $447,203(0.61)$ & $297,914(0.60)$ \\
\hline Female & $579,532(0.38)$ & $290,571(0.39)$ & $196,656(0.40)$ \\
\hline- & 248 & 1 & 0 \\
\hline \multicolumn{4}{|l|}{ Detection } \\
\hline Passive & $1,141,723(0.75)$ & $561,082(0.76)$ & $382,961(0.77)$ \\
\hline Active & $371,168(0.25)$ & $176,693(0.24)$ & $111,609(0.23)$ \\
\hline
\end{tabular}

${ }^{1} \mathrm{n}(\%),{ }^{2}$ Unknown/not applicable, ${ }^{3}$ P. falciparum gametocytes.

Table 3: Proportion of timely treatments, Legal Amazon, 2007-2019

\begin{tabular}{|c|c|c|c|c|c|c|}
\hline \multirow[b]{2}{*}{ Characteristic } & \multicolumn{6}{|c|}{ Autóctones (ITST<48h) } \\
\hline & $07-11$ & $\mathrm{p}$-value & $12-16$ & $\mathrm{p}$-value & $17-19$ & p-value \\
\hline Total & $63 \%$ & & $63 \%$ & & $61 \%$ & \\
\hline Detection & & $<0.001$ & & $<0.001$ & & $<0.001$ \\
\hline Active & $68 \%$ & & $70 \%$ & & $69 \%$ & \\
\hline Passive & $61 \%$ & & $60 \%$ & & $58 \%$ & \\
\hline Level of schooling & & $<0.001$ & & $<0.001$ & & $<0.001$ \\
\hline Elementary - Incomplete & $63 \%$ & & $63 \%$ & & $61 \%$ & \\
\hline High school - Incomplete & $59 \%$ & & $59 \%$ & & $56 \%$ & \\
\hline College - Incomplete & $50 \%$ & & $56 \%$ & & $55 \%$ & \\
\hline College - Complete & $59 \%$ & & $59 \%$ & & $56 \%$ & \\
\hline Pregnancy status & & $<0.001$ & & $<0.001$ & & $<0.001$ \\
\hline 1st trimester & $52 \%$ & & $60 \%$ & & $55 \%$ & \\
\hline 2nd trimester & $51 \%$ & & $60 \%$ & & $59 \%$ & \\
\hline 3rd trimester & $55 \%$ & & $62 \%$ & & $62 \%$ & \\
\hline Pregnant, age unknown & $61 \%$ & & $65 \%$ & & $64 \%$ & \\
\hline Non-pregnant & $63 \%$ & & $62 \%$ & & $60 \%$ & \\
\hline Age group & & $<0.001$ & & $<0.001$ & & $<0.001$ \\
\hline 0 a 14 & $67 \%$ & & $69 \%$ & & $68 \%$ & \\
\hline 15 a 64 & $61 \%$ & & $59 \%$ & & $57 \%$ & \\
\hline $65+$ & $59 \%$ & & $59 \%$ & & $57 \%$ & \\
\hline Occupation & & $<0.001$ & & $<0.001$ & & $<0.001$ \\
\hline Agriculture & $61 \%$ & & $61 \%$ & & $60 \%$ & \\
\hline
\end{tabular}




\begin{tabular}{|c|c|c|c|c|c|c|}
\hline Domestic service & $61 \%$ & & $56 \%$ & & $57 \%$ & \\
\hline Gold panning/mining & $58 \%$ & & $55 \%$ & & $52 \%$ & \\
\hline Other & $64 \%$ & & $65 \%$ & & $62 \%$ & \\
\hline Parasite count (crosses) & & $<0.001$ & & $<0.001$ & & $<0.001$ \\
\hline$<1 / 2$ & $67 \%$ & & $69 \%$ & & $66 \%$ & \\
\hline 1 & $63 \%$ & & $62 \%$ & & $61 \%$ & \\
\hline 2 & $59 \%$ & & $57 \%$ & & $55 \%$ & \\
\hline 3 & $57 \%$ & & $55 \%$ & & $51 \%$ & \\
\hline 4 & $59 \%$ & & $63 \%$ & & $61 \%$ & \\
\hline Parasite species & & $<0.001$ & & $<0.001$ & & $<0.001$ \\
\hline P. falciparum & $65 \%$ & & $66 \%$ & & $64 \%$ & \\
\hline$P$. vivax & $63 \%$ & & $63 \%$ & & $61 \%$ & \\
\hline $\mathrm{g} P f$ & $59 \%$ & & $61 \%$ & & $62 \%$ & \\
\hline Mixed & $62 \%$ & & $63 \%$ & & $66 \%$ & \\
\hline Other & $52 \%$ & & $52 \%$ & & $64 \%$ & \\
\hline Race & & $<0.001$ & & $<0.001$ & & $<0.001$ \\
\hline Yellow & $55 \%$ & & $58 \%$ & & $57 \%$ & \\
\hline White & $57 \%$ & & $60 \%$ & & $56 \%$ & \\
\hline Indigenous & $70 \%$ & & $64 \%$ & & $71 \%$ & \\
\hline Brown & $61 \%$ & & $63 \%$ & & $58 \%$ & \\
\hline Black & $58 \%$ & & $60 \%$ & & $53 \%$ & \\
\hline Municipal risk & & $<0.001$ & & $<0.001$ & & $<0.001$ \\
\hline High & $66 \%$ & & $66 \%$ & & $64 \%$ & \\
\hline Medium & $56 \%$ & & $55 \%$ & & $54 \%$ & \\
\hline Low & $43 \%$ & & $46 \%$ & & $48 \%$ & \\
\hline Sexo & & $<0.001$ & & $<0.001$ & & $<0.001$ \\
\hline Female & $64 \%$ & & $64 \%$ & & $62 \%$ & \\
\hline Male & $63 \%$ & & $62 \%$ & & $60 \%$ & \\
\hline
\end{tabular}

Source: SIVEP - Malária.

1 Log-rank test 